\title{
The Effect of Residual Stresses on the Coercive Field Strength of Drawn Wires
}

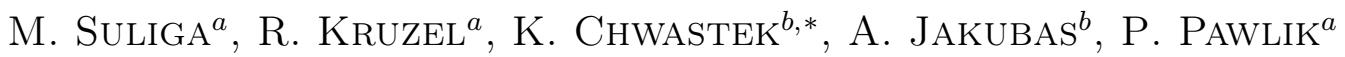 \\ ${ }^{a}$ Faculty of Materials Processing and Production Technology, Częstochowa University of Technology, \\ al. Armii Krajowej 19, 42-201 Częstochowa, Poland \\ ${ }^{b}$ Faculty of Electrical Engineering, Częstochowa University of Technology, \\ al. Armii Krajowej 17, 42-201 Częstochowa, Poland
}

\begin{abstract}
Residual stresses occurring in drawn wires due to technological process affect their quality, which in turn may have a substantial impact on safety of use and "life" of ready-made products. Measurements of magnetic properties of the wires like coercive field strength may be useful for monitoring the level of residual stresses. The present paper examines the relationship between the drawing speed and the coercive field strength in high carbon wires. It has been found that for drawing speeds not exceeding $20 \mathrm{~m} / \mathrm{s}$ the coercive field strength is proportional to residual stresses on wire surface.
\end{abstract}

DOI: 10.12693/APhysPolA.131.1114

PACS/topics: 61.72.Hh, 75.60.-d, 75.60.Ej

\section{Introduction}

Monitoring of residual stress level is crucial for safety reasons in many applications, therefore the engineering community is deeply interested in non-destructive testing (NDT) methods [1]. Magnetic measurements may be used with success for NDT purposes [2,3].

The value of coercive field strength in soft magnetic materials depends on a number of factors (excitation conditions, micro-structure, chemical composition, anisotropy etc.). It is significantly affected by the presence of dislocations [4] and inclusions in the crystalline structure acting as pinning sites for domain wall movement [5-8]. Kersten developed a simplified model of coercivity which describes the pinning mechanism on defects significantly larger than domain walls [9]. Later Néel modified the existing theory to account the concept of flexible domain walls [10]. Vicena focused on the influence of internal stress on coercivity introducing a simplified model of stress distribution similar to the one considered by Néel [11]. Málek carried out extensive tests in order to verify Vicena's theory for different iron- and nickel-based soft magnetic materials $[12,13]$. More recently Timofeev and Kustov examined the dependences of coercive field strength on dislocation density for silicon steels used in electrical engineering [14].

This paper focuses on the effect of variation of wire drawing speed on the value of coercive field strength in high carbon steel wires. In previous work the authors have attempted to use the major hysteresis loop of drawn wire as an indicator of residual stress $[15,16]$. The phe-

\footnotetext{
* corresponding author; e-mail: krzysztof . chwastek@gmail.com
}

nomenological Takács [17] and Jiles-Atherton [18] descriptions, which included the Sablik extension to the effective field [19], were used for this purpose. Despite some encouraging results it was found that in order to obtain a good agreement between the measured and modelled hysteresis curves it was necessary to introduce the experimental $H_{c}$ values into analytical expressions.

\section{Measurements}

The wires examined in the present study have been drawn in industrial conditions using a modern multi-step drawing machine Koch KGT 25/12. The material used in the investigation is C78DP high carbon $(0.78 \% \mathrm{C})$ steel. Its chemical composition is presented in Table I. It is given in weight $\%$ and the remainder is Fe. Measurements of magnetic properties have been determined using a VSM 7301 from Lakeshore.

TABLE I

Chemical composition of C78DP steel.

\begin{tabular}{c|c|c|c|c|c|c|c|c|c}
\hline \hline $\mathrm{C}$ & $\mathrm{Mn}$ & $\mathrm{Si}$ & $\mathrm{P}$ & $\mathrm{S}$ & $\mathrm{Cr}$ & $\mathrm{Ni}$ & $\mathrm{Cu}$ & $\mathrm{Al}$ & $\mathrm{N}$ \\
\hline 0.790 & 0.610 & 0.200 & 0.010 & 0.013 & 0.060 & 0.020 & 0.050 & 0.003 & 0.003
\end{tabular}

\section{Results and discussion}

Figure 1 depicts the experimental dependence of coercive field strength on drawing speed for the examined high carbon wires. It can be stated that coercive field strength increases linearly upon the increase of drawing speed. The observed trend may be explained by taking into account that the value of coercive field strength is proportional to dislocation density.

Rieder carried out studies on the relationship between plastic deformation and dislocation density [20]. He noticed an almost linear relationship between these quantities. This suggestion has been indirectly verified in the 


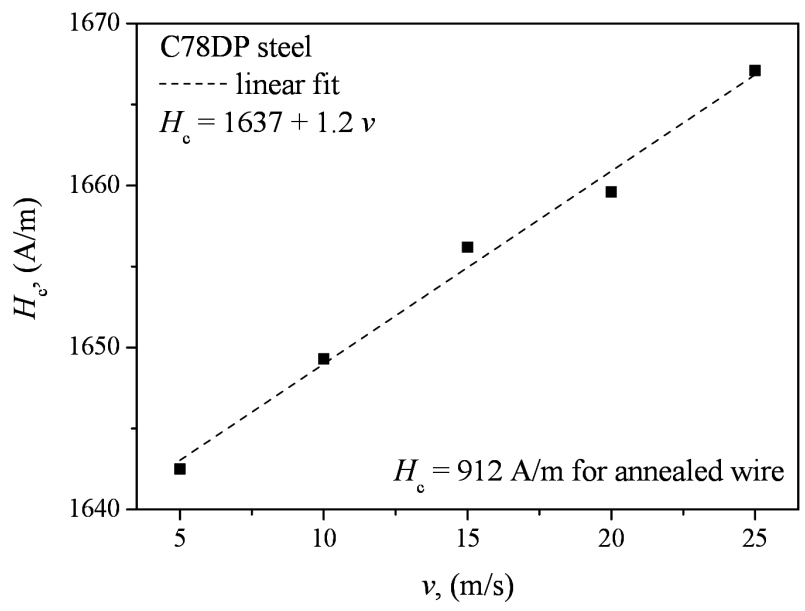

Fig. 1. Experimental dependence of coercive field strength on drawing speed.

present paper by carrying out experimental testing of mechanical properties of ready-made wires with Zwick/Z100 testing machine. Moreover, the level of residual stress in the samples has been determined with Schepers-Peiter method, cf. Fig. 2.

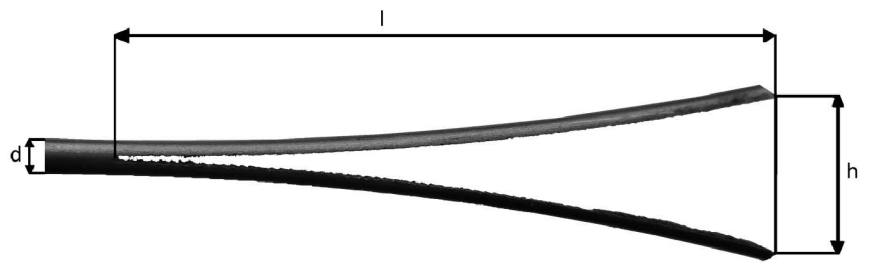

Fig. 2. Determination of longitudinal residual stress with the Schepers-Peiter method [21].

The concept of the Schepers-Peiter approach relies on the measurement of deflection of longitudinally cut wire, so this is a destructive method. Residual stress on the wire surface is given with the expression

$$
\sigma_{\text {res }}=1.1376 E R h / l^{2} \text {, }
$$

where $E$ is Young modulus ( $\mathrm{MPa}), R$ is wire radius ( $\mathrm{mm}$ ), $h$ is deflection of wire ends $(\mathrm{mm})$, whereas $l$ is cutting length $(\mathrm{mm})$.

Figure 3 depicts the obtained results. It can be stated that the tensile strength $R_{m}$ of ready-made wires and longitudinal residual stress $\sigma_{\text {res }}$ are correlated. For higher drawing speeds one can observe a sudden increase in residual stress level. This may be due to the increased non-uniformity of deformations (higher non-dilatational strain, substantial temperature jump in near-surface layer) [21]. From Fig. 3 it follows that two distinctive fits may be proposed for the dependence $\sigma_{\text {res }}(v)$ for drawing speeds below and above $20 \mathrm{~m} / \mathrm{s}$. The respective equations are $\sigma_{\text {res }}(v)=719+2.44 v$ and $\sigma_{\text {res }}(v)=488+13.96 v$. Taking this into account, one may reconstruct the dependence of coercive field strength on residual stress in the form $H_{c}=1297+0.47 \sigma_{\text {res }}$, which is depicted in Fig. 4 .

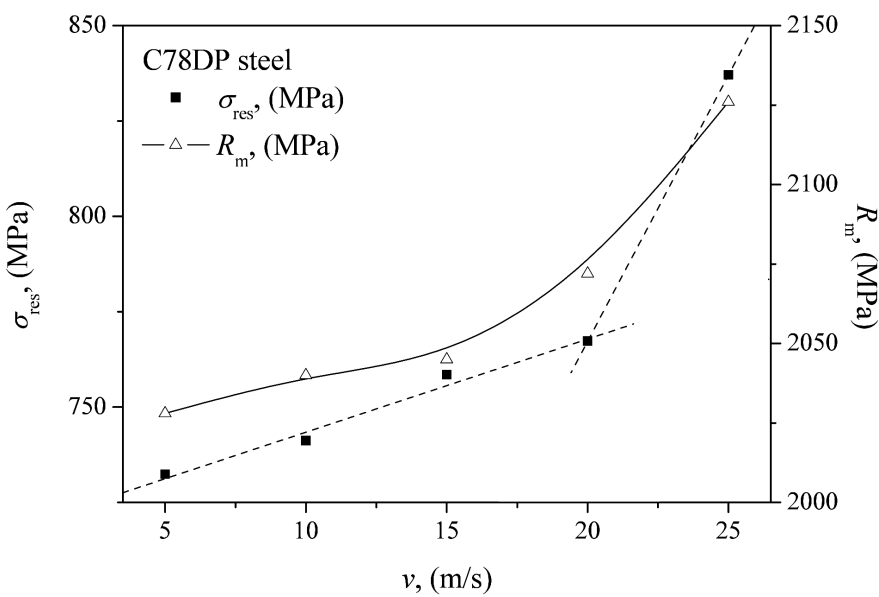

Fig. 3. Experimental dependences of longitudinal residual stress and offset yield strength on drawing speed for ready-made wires.

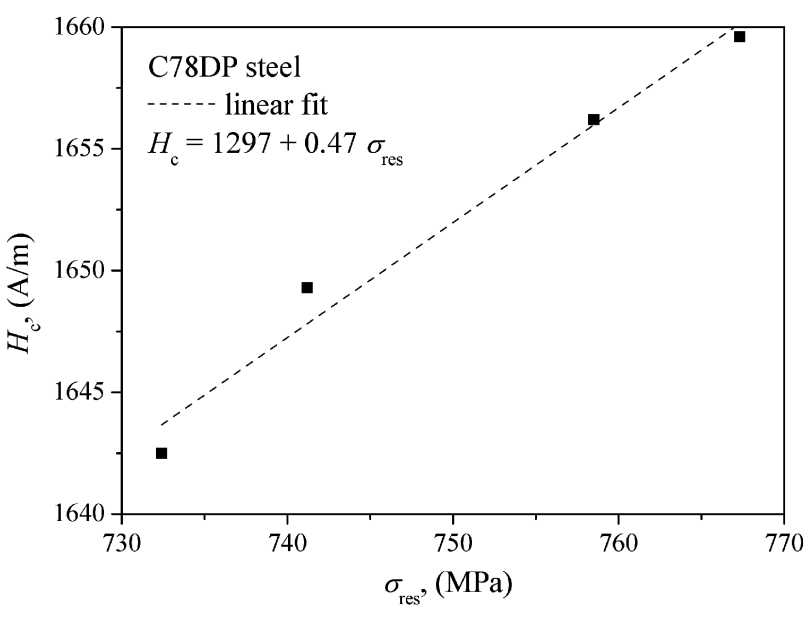

Fig. 4. Reconstructed dependence of coercive field strength on residual stress for wires drawn at speeds less than $20 \mathrm{~m} / \mathrm{s}$.

\section{Conclusions}

Measurements of coercive field strength for wires drawn with different speeds have been carried out using a VSM. The quantity is highly sensitive against variations of technological process, therefore it might be useful for its optimization. Coercive field strength depends linearly on drawing speed, which may be understood taking into account the internal deformation in the wire. The state of the material in turn affects the mechanical properties of ready-made wires like tensile strength $R_{m}$ and the level of residual stress $\sigma_{\text {res }}$. The measurement results indicate that the value of coercive field strength might be a direct indicator of residual stress on wire surface. Thus measurements of coercive field strength may find a wide application in NDT as a quick and cheap alternative to mechanical methods such as the Schepers-Peiter approach. 


\section{References}

[1] G.S. Schajer, C.O. Ruud, in: Practical Residual Stress Measurement Methods, Ed. G.S. Schajer, Wiley, New York 2013.

[2] D.C. Jiles, NDT Int. 21, 311 (1988).

[3] G.V. Bida, A.P. Nichipuruk, Rus. J. Nondestruct. Test. 36, 707 (2000).

[4] J.P. Hirth, J. Lothe, Theory of Dislocations, Krieger Publ. Co., Malabar 1992.

[5] L.J. Dijkstra, C. Wert, Phys. Rev. 79, 979 (1950).

[6] W.D. Nix, R.A. Huggins, Phys. Rev. 135, A401 (1964).

[7] D.I. Paul, AIP Conf. Proc. 29, 545 (1976).

[8] H.-R. Hilzinger, H. Kronmüller, Physica B 86-88, 1365 (1977).

[9] M. Kersten, in: Probleme der technischen Magnetisierungskurve, Ed. R. Becker, Springer, Berlin 1938 (in German).

[10] L. Néel, Ann. Univ. Grenoble 22, 299 (1946) (in French).

[11] F. Vicena, Czechosl. J. Phys. 4, 419 (1954) (in Russian).
[12] Z. Málek, Czechosl. J. Phys. 7, 152 (1957) (in German).

[13] Z. Málek, Czechosl. J. Phys. 7, 335 (1957) (in German).

[14] I.A. Timofeev, E.F. Kustov, Rus. Phys. J. 49, 260 (2006).

[15] M. Suliga, K. Chwastek, P. Pawlik, Nondestruct. Test. Eval. 29, 123 (2014).

[16] M. Suliga, L. Borowik, K. Chwastek, P. Pawlik, Przegl. Elektrotechn. 12, 161 (2014) (in Polish).

[17] J. Takács, Mathematics of Hysteretic Phenomena, Wiley-VCH, Weinheim 2003.

[18] D.C. Jiles, D.L. Atherton, J. Phys. D Appl. Phys. 17, 1265 (1984).

[19] M.J. Sablik, D.C. Jiles, IEEE Trans. Magn. 29, 2113 (1993).

[20] G. Rieder, Z. Angew. Phys. 9, 187 (1957) (in German).

[21] M. Suliga, Analysis of the Multipass Steel Wire Drawing with High Speed in Conventional and Hydrodynamical Dies, Wyd. WIPMiFS, Częstochowa 2013. 